\title{
Synthesis and controlled release of cloprop herbicides from cloprop-layered double hydroxide and cloprop-zinc-layered hydroxide nanocomposites
}

\author{
Norhayati Hashim ${ }^{1,2 *}$, Mohd Zobir Hussein ${ }^{3}$, Illyas Md Isa ${ }^{1,2}$, Azlan Kamari ${ }^{1,2}$, \\ Azmi Mohamed ${ }^{1,2}$, Adila Mohamad Jaafar ${ }^{3}$, Hafsah Taha ${ }^{1}$ \\ ${ }^{1}$ Department of Chemistry, Faculty of Science and Mathematics, Universiti Pendidikan Sultan Idris, Tanjong Malim, Malaysia \\ ${ }^{2}$ Nanotechnology Research Centre, Faculty of Science and Mathematics, Universiti Pendidikan Sultan Idris, Tanjong Malim, Malaysia \\ ${ }^{3}$ Department of Chemistry, Faculty of Science, Universiti Putra Malaysia, Serdang, Malaysia \\ Email: *norhayati.hashim@fsmt.upsi.edu.my
}

Received 11 October 2013; revised 11 November 2013; accepted 17 November 2013

Copyright (C) 2014 Norhayati Hashim et al. This is an open access article distributed under the Creative Commons Attribution License, which permits unrestricted use, distribution, and reproduction in any medium, provided the original work is properly cited. In accordance of the Creative Commons Attribution License all Copyrights @ 2014 are reserved for SCIRP and the owner of the intellectual property Norhayati Hashim et al. All Copyright (c) 2014 are guarded by law and by SCIRP as a guardian.

\section{ABSTRACT}

Two phenoxyherbicide nanocomposites, namely cloprop-layered double hydroxide and cloprop-zinclayered hydroxide nanocomposites, have been synthesized by using co-precipitation and direct reaction method. PXRD pattern showed an expansion of interlayer spacing with the value of $21.0 \AA$ and $22.7 \AA$ for cloprop-layered double hydroxide and cloprop-zinclayered hydroxide nanocomposite, respectively. It is evident from FTIR and elemental analyses that both nanocomposites were successfully intercalated between the interlayers of layered metal hydroxide. Controlled release of cloprop anion from interlayer of nanocomposites for both cloprop-layered double hydroxide and cloprop-zinc-layered hydroxide nanocomposite into phosphate solution was rapid initially and slow thereafter. The percentage of accumulated release of cloprop anion from cloprop-zinc-layered hydroxide nanocomposite was slightly higher than that from cloprop-layered double hydroxide nanocomposite. Kinetic behavior of cloprop release was governed by pseudo-second-order for cloprop-layered double hydroxide nanocomposite while parabolic diffusion for cloprop-zinc-layered hydroxide nanocomposite. Results from this study highlight the potential of both nanocomposites as capsulated material for controlled release of cloprop phenoxyherbicides anion.

\section{KEYWORDS}

Cloprop; Cloprop-Layered Double Hydroxide;

*Corresponding author.
Cloprop-Zinc-Layered Hydroxide; Nanocomposite; Controlled Release; Kinetic Study

\section{INTRODUCTION}

Environmental problems associated with the use of highly mobile herbicides are of current concern because of the increasing presence of these agrochemicals in ground and surface waters. Anionic herbicides are of particular concern because they are weakly retained by most of the components of soil sediment, so they remain dissolved in the soil solution and can rapidly move around [1]. One approach to minimizing such transport losses is to use controlled release formulation in which the herbicides are incorporated in a matrix or carrier before application, thereby limiting the amount available for unwanted processes [2]. In this study, LDHs with general formula of

$\left[\mathrm{M}_{1-\mathrm{x}}^{2+} \mathrm{M}_{\mathrm{x}}^{3+}(\mathrm{OH})_{2}\right]^{\mathrm{x}+}\left(\mathrm{A}^{\mathrm{n}-}\right)_{\mathrm{x} / \mathrm{n}} \cdot \mathrm{mH}_{2} \mathrm{O}$

and LMHs with general formula represented by

$\mathrm{M}^{2+}(\mathrm{OH})_{2-\mathrm{x}}\left(\mathrm{A}^{\mathrm{n}-}\right)_{\mathrm{x} / \mathrm{n}} \cdot \mathrm{mH}_{2} \mathrm{O}$ have been chosen to be studied as herbicides controlled release formulation. $\mathrm{M}^{2+}$ is the metallic cation such as $\mathrm{Mg}^{2+}, \mathrm{Zn}^{2+}, \mathrm{Co}^{2+}, \mathrm{Ni}^{2+}$ and $\mathrm{M}^{3+}$ is a trivalent metal ion such as $\mathrm{Al}^{3+}, \mathrm{Fe}^{3+}, \mathrm{Cr}^{3+}, \mathrm{Ga}^{3+}$, $\mathrm{Ni}^{3+}, \mathrm{Mn}^{3+}[3,4] . A$ is a counterion with $\mathrm{n}^{-}$charge [5]. This is a safe herbicide system to minimize and prevent the herbicides from direct exposure to environment. Due to these properties, LDH and LMH have a huge opportunity in industrial and environmental research as absorbent [6], chemical sensor [7-9], catalyst [10], drug delivery 
[11] and controlled release formulation [12]. Co-precipitation method has been used to prepare cloprop$\mathrm{Zn}$ /Al-layered double hydroxide (cloprop-LDH), meanwhile, cloprop-zinc-layered hydroxide (cloprop-ZLH) is prepared by using a direct reaction method. Cloprop (2(3chlorophenoxy)propionic acid) is one of phenoxyherbicides widely used in maize, wheat and corn plantations. Controlled release study of cloprop from its nanocomposite was done into various solutions of sodium phosphate concentrations. Four kinetic orders were applied in this study in order to understand the release behavior of cloprop into different aqueous solutions.

\section{EXPERIMENTAL}

\subsection{Preparation of Nanocomposites}

All chemicals used in this synthesis were obtained from various chemical suppliers and used without any further purification. All solutions were prepared using deionized water. The preparation of the nanocomposite was carried out using direct co-precipitation method for clopropLDH and direct reaction method for cloprop-ZLH. For cloprop-LDH, a mother liquor containing $\mathrm{Zn}^{2+}$ and $\mathrm{Al}^{3+}$ cations with $\mathrm{Zn}$ to $\mathrm{Al}$ initial molar ratio $\mathrm{R}=3.0$ and 0.05 $\mathrm{M}$ to $0.3 \mathrm{M}$ cloprop were prepared. The resulting solution was adjusted to $\mathrm{pH} 7.50 \pm 0.02$ by drop wise addition of aqueous $\mathrm{NaOH}(2.0 \mathrm{M})$. The reaction was carried out under nitrogen atmosphere. The resulting precipitate was aged at $70^{\circ} \mathrm{C}$ in an oil bath shaker for 18 hours. The synthesized material was then centrifuged, thoroughly washed with deionized water and dried in an oven at $70^{\circ} \mathrm{C}$. The resulting nanocomposite was then powdered and stored in a sample bottle for further use and characterizations.

Meanwhile cloprop-ZLH was synthesized by mixing $0.05 \mathrm{~g}$ of $\mathrm{ZnO}$ (pure commercial zinc oxide, reagent ACS, Acros Organics) into $100 \mathrm{ml}$ deionized water. Solutions of cloprop acid with concentrations of $0.05 \mathrm{M}$ to $0.3 \mathrm{M}$ were added into the $\mathrm{ZnO}$ solution. The precipitate was aged at $70^{\circ} \mathrm{C}$ in an oil bath shaker for 18 hours. The synthesized material was then centrifuged, thoroughly washed with deionized water and dried in an oven at $70^{\circ} \mathrm{C}$. The resulting material was then powdered and stored in a sample bottle for further use and characterizations.

\subsection{Instrumentation}

Powder X-ray diffraction patterns were recorded at $2^{\circ}$ $60^{\circ}$ on an ITAL 2000 diffractometer using $\mathrm{Cu} \mathrm{K}_{\alpha}$ radiation at $40 \mathrm{kV}$ and $30 \mathrm{~mA}$. FTIR spectra of the materials were recorded over the range $400-4000 \mathrm{~cm}^{-1}$ on a Perkin-Elmer 1752X Spectrophotometer using $\mathrm{KBr}$ disc method. The elemental composition of the samples molar ratio of the resulting nanocomposite were determined by using inductively couple plasma-atomic emission spectrometry (ICP-AES), using a Perkin Elmer Spectrophotometer model Optima 2000DV under standard condition and CHNS analyzer model CHNS-932 (LECO). Thermogravimetric and differential thermogravimetric analyses (TGA/DTG) were carried out using a Mettler Toledo TGA/SDTA851 thermogravimetric analyzer with heating rate of $10^{\circ} \mathrm{C} \cdot \mathrm{min}^{-1}$ between $35^{\circ} \mathrm{C}-1000^{\circ} \mathrm{C}$, under nitrogen flow rate of about $50 \mathrm{ml} \cdot \mathrm{min}^{-1}$.

The release of cloprop from its interlamellae host into the release media, the aqueous solutions at various initial concentrations of sodium phosphate was done by adding about $0.20 \mathrm{~g}$ of the nanocomposite into $500 \mathrm{~mL}$ of the aqueous solution. The accumulated amount of cloprop released into the solution was measured at preset time at $\lambda_{\max }=217 \mathrm{~nm}$ respectively, using a Perkin Elmer UVvisible Spectrophotometer Lambda 35.

\section{RESULT AND DISCUSSIONS}

\subsection{Powder X-Ray Diffraction}

Figure 1(a) shows powder XRD patterns of clopropLDH nanocomposite prepared by co-precipitation method at $\mathrm{R}=3$ (ratio zinc to aluminium) with concentration of cloprop $0.05 \mathrm{M}$ to $0.3 \mathrm{M}$. As shown in the fig- ure, the intercalation started at cloprop concentration of 0.05 $\mathrm{M}$ with a small peak at low angle of $2 \theta$ below $10^{\circ}$ but the peak of unintercalated $\mathrm{Zn} / \mathrm{Al}-\mathrm{LDH}$ remained (peak with basal spacing of $8.9 \AA$ ). As the concentration of cloprop is increased from $0.1 \mathrm{M}$ to $0.3 \mathrm{M}$, the intensity of intercalation peak increased which corresponded with high crystallinity of resulting material when cloprop was introduced. As reported, the mechanism of co-precipitation method relies upon the condensation of hexa-aqua complexes in solution in order to form the brucite-like layers with a distribution of both metallic cations and with solvated interlayer anions $[3,13]$. As shown in the figure, cloprop intercalated into the layer of LDH shows a pure phase of nanocomposites with sharp and intense peak at low angle of $2 \theta$ below $10^{\circ}$ at $0.2 \mathrm{M}$ cloprop due to high crystallinity of the materials with the basal spacing (003) of $21.0 \AA$. The expanded basal spacing was attributed to the bigger size and higher density of cloprop intercalated between the interlayer of brucite-type layer compared to nitrate anions.

Figure 1(b) shows of cloprop-ZLH nanocomposite synthesized by direct reaction method at $0.05 \mathrm{M}$ to $0.3 \mathrm{M}$ cloprop. Generally, all PXRD diffraction of clopropZLH showed intercalation peak at low $2 \theta$ angle reflection through the dissociation-deposition mechanism [11,14]. All cloprop-ZLH nanocomposite produced sharp and symmetrical peaks, suggesting a well ordered stacking layer. $\mathrm{ZnO}$ phase appeared in all of PXRD diffraction which is due to incomplete reaction. As shown in the 


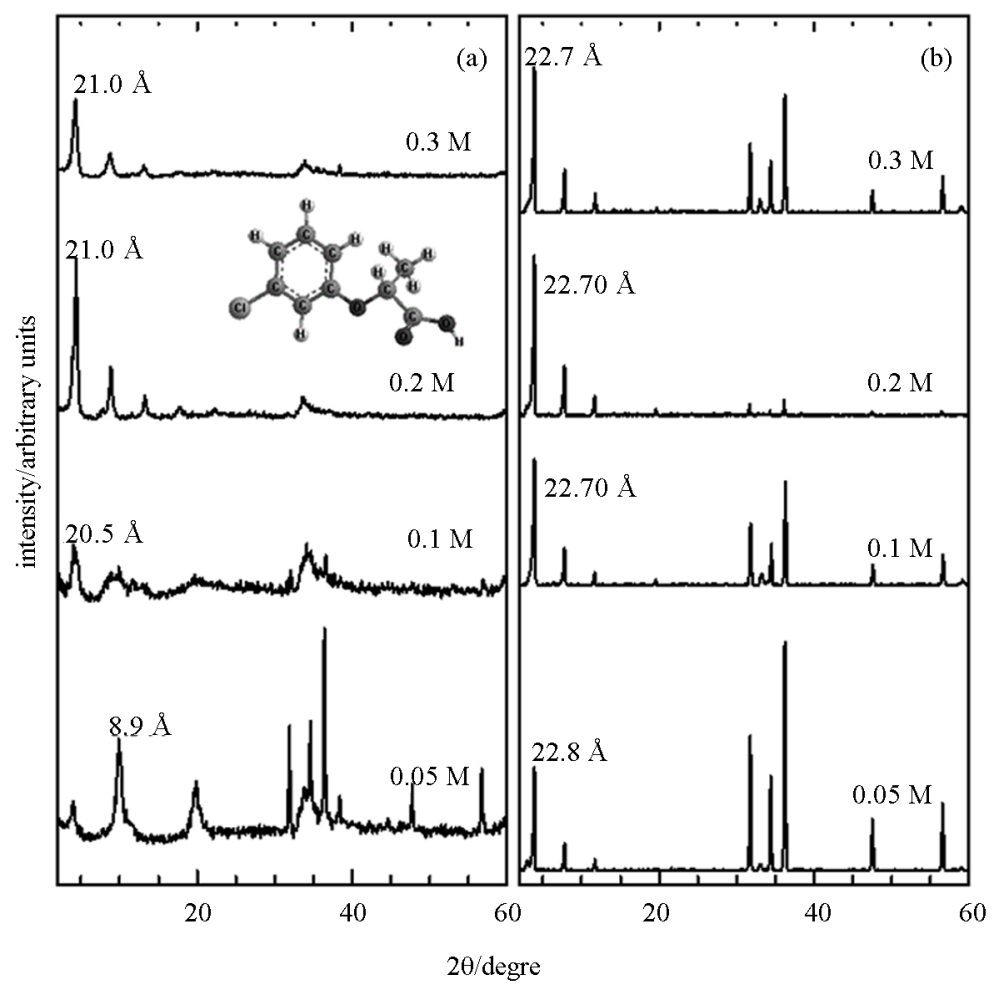

Figure 1. PXRD patterns of cloprop-LDH (a) and cloprop-ZLH (b) nanocomposite at different concentration of cloprop anion. Inset is the molecular structure of cloprop.

figure, cloprop-ZLH synthesized with $0.2 \mathrm{M}$ cloprop showed high crystallinity and the least of $\mathrm{ZnO}$ phase compared to others with basal spacing of $22.7 \AA$. For this reason, cloprop-ZLH at $0.2 \mathrm{M}$ has been chosen for further characterization and elemental analysis.

\subsection{FTIR}

The presence of the intercalated species in the layered hydroxide materials were also supported by FTIR results (Figure 2). FTIR spectra for cloprop showed a broad band at $2959 \mathrm{~cm}^{-1}$ which is attributed to the O-H stretching vibration. A sharp band at $1715 \mathrm{~cm}^{-1}$ is due to the stretching of $\mathrm{C}=\mathrm{O}$ and bands at 1465 and $1404 \mathrm{~cm}^{-1}$ are attributed to stretching vibrations of aromatic ring $\mathrm{C}$ $=\mathrm{C}$. A strong band at 1277 and $1215 \mathrm{~cm}^{-1}$ were due to the symmetric and asymmetric stretching modes of C-O-C of the cloprop anions while a sharp band at 746 $\mathrm{cm}^{-1}$ is due to $\mathrm{C}-\mathrm{Cl}$ stretching band of both anions [15].

The FTIR spectrum of cloprop-LDH and cloprop-ZLH synthesized using $0.2 \mathrm{M}$ cloprop are also shown in Figure 2. As expected, the spectrum resembles a mixture of both FTIR spectra of cloprop and $\mathrm{Zn} / \mathrm{Al}-\mathrm{LDH}$, indicating that both functional groups of cloprop and $\mathrm{Zn} / \mathrm{Al}-\mathrm{LDH}$ are present together, except for the peak at $1389 \mathrm{~cm}^{-1}$ and $1713 \mathrm{~cm}^{-1}$ corresponding to the nitrate anions and carboxylic group. The presence of new peaks at around
$1577 \mathrm{~cm}^{-1}$ and $1333 \mathrm{~cm}^{-1}$ for cloprop-LDH nanocomposite were due to the $\mathrm{C}=\mathrm{O}$ carboxylate anion, which confirm the presence of cloprop in the anionic form in the interlayer of the Zn/Al-LDH [16]. This shows the cloprop has higher affinity than nitrate towards the inorganic interlamellae, thus occupies the interlamellae space between the inorganic layers and prevents further cointercalation of nitrate anion.

This is further supported by the CHNS result, which shows the absence of nitrogen in both nanocomposite. FTIR spectrum of cloprop-ZLH nanocomposite (Figure 2) shows the characteristic of the bands of pure cloprop. This indicates the cloprop anions have been intercalated into the interlayer galleries of the ZLH. Some of the bands are slightly shifted in position, presumably due to the interaction between cloprop anions and the host interlayer as a result of the intercalation process.

Intense bands at 1583 and $1399 \mathrm{~cm}^{-1}$ for cloprop-ZLH nanocomposite are attributed to antisymmetric and symmetric carboxylate stretching of the anion. The bands at 1470 and $1409 \mathrm{~cm}^{-1}$ were due to the stretching vibrations of the aromatic ring $\mathrm{C}=\mathrm{C}$. A strong band at 869 $\mathrm{cm}^{-1}$ is attributed to $\mathrm{C}-\mathrm{Cl}$ stretching and the bands at 736 and $772 \mathrm{~cm}^{-1}$ due to $\mathrm{C}-\mathrm{H}$ vibration of benzene ring in cloprop-ZLH. This indicates the successful intercalation of the guest anion, cloprop. 


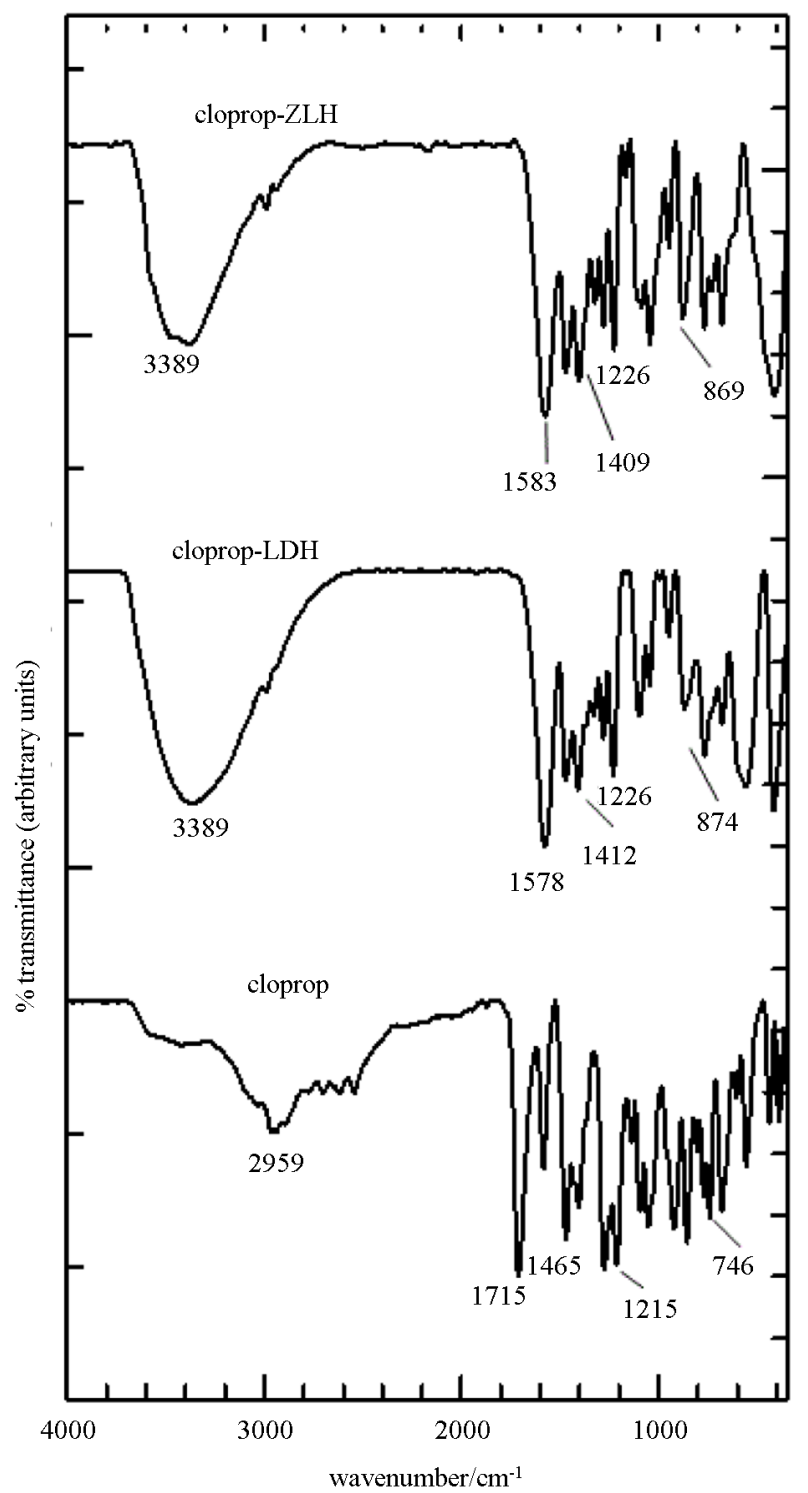

Figure 2. FTIR spectra of cloprop, cloprop-LDH and clopropZLH nanocomposites.

\subsection{Elemental Analysis}

Table 1 shows elemental and organic content of cloprop-LDH and cloprop-ZLH. Elemental analysis shows the molar ratio of $\mathrm{Zn}$ to $\mathrm{Al}$ in clorrop-LDH 2.9 compared to 3.0 for the value initially prepared for the mother liquor. This indicates that the $\mathrm{Zn}$ to $\mathrm{Al}$ molar ratio in the resulting synthesized materials was adjusted accordingly for the formation of the positively charged inorganic layers to compensate the negatively charged intercalated anion so that the resulting materials cloprop-LDH is neutrally charged [17].

As shown in the table, the estimated percentage of cloprop intercalated into the interlayer are not much different for both nanocomposites which indicated same amount of cloprop anion intercalated between the inter-
Table 1. Elemental composition of cloprop-LDH and clopropZLH nanocomposites.

\begin{tabular}{cccccccc}
\hline Sample & $\mathrm{d}(\AA)$ & Zn/Al ratio & $\mathrm{X}_{\mathrm{Al}}$ & $\mathrm{N}$ & $\mathrm{C}$ & $\mathrm{Zn}$ & Cloprop $^{\mathrm{a}}$ \\
\hline Cloprop-LDH & 21.0 & 2.9 & 0.25 & - & 20.6 & - & 38.3 \\
Cloprop-ZLH & 22.7 & - & - & - & 20.8 & 34.8 & 38.8 \\
\hline
\end{tabular}

a estimated using CHNS analysis.

layer of brucite-type layer for cloprop-LDH and cloprop-ZLH nanocomposite. The elemental analysis shows that cloprop-LDH and cloprop-ZLH contained 20.6\% and $20.8 \%$ carbon ( $\mathrm{w} / \mathrm{w}$ ) and loading percentages of cloprop anion in the nanocomposite is $38.3 \%$ and $38.8 \%$ (w/w), respectively. The results showed that cloprop anion was successfully intercalated between the interlayer of layered materials.

\subsection{Thermal Analysis}

TGA/DTG thermogravimetric analysis obtained for the choprop-LDH, cloprop-ZLH and cloprop are reported in Figures 3(a)-(c) and Table 2. For cloprop, thermal studies show that the maximum temperature was observed at $204^{\circ} \mathrm{C}$ compared to $350^{\circ} \mathrm{C}$ and $381^{\circ} \mathrm{C}$ to the clopropLDH and cloprop-ZLH nanocomposites. This indicates that cloprop encapsulated into the inorganic interlamellae is thermally more stable than their counterparts in the sodium salt form.

For cloprop-LDH nanocomposite, three stages of weight loss were observed. Meanwhile, cloprop-ZLH showed two stages of weight loss. The first stage is the weight loss due to the physically adsorbed water and interlayer water which could be seen at around $35^{\circ} \mathrm{C}$ $200^{\circ} \mathrm{C}$ followed by a weight loss due to the removal of interlayer anion and dehydroxylation of the hydroxyl layer which could be observed at $201^{\circ} \mathrm{C}-600^{\circ} \mathrm{C}$. The weight losses for encapsulated organic moiety of the nanocomposite are at $350^{\circ} \mathrm{C}$ (cloprop-LDH) and $381^{\circ} \mathrm{C}$ (cloprop-ZLH). The third stage was characterized by combustion of the organic species, leaving only a relatively less volatile, metal oxide.

\subsection{Controlled Release Study}

Controlled release of cloprop anion from cloprop-LDH, cloprop-ZLH nanocomposite into sodium phosphate had been done at different concentrations of sodium phosphate which is shown in Figures 4(a) and (b).

Based on the components of rain water, phosphate solution was chosen as the medium for release of cloprop phenoxyherbicides. Since the research was carried out in the laboratory, the results collected will give us the information and patterns of releasing cloprop phenoxyherbicides from the interlayer of nanocomposite, some adjustments or modifications of the involved method need 

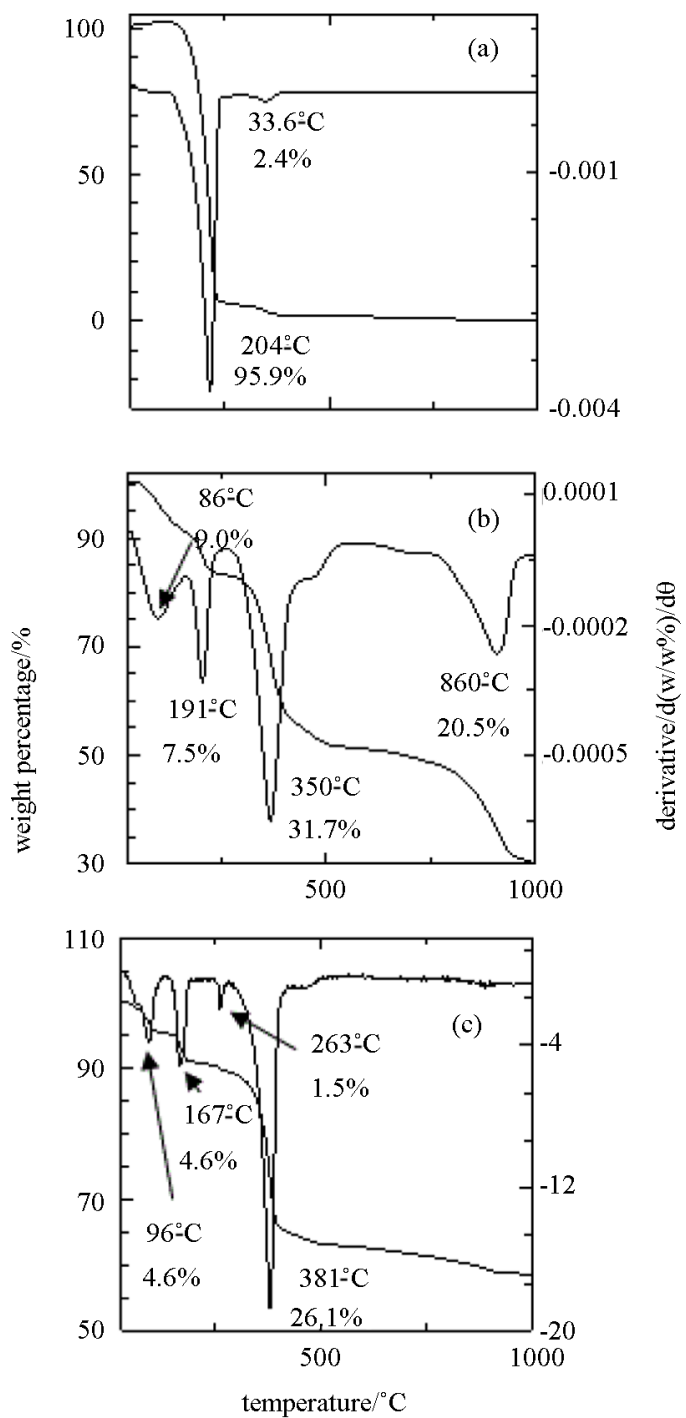

Figure 3. TGA/DTG thermograms of cloprop (a), cloprop-LDH (b) and cloprop-ZLH (c) nanocomposites.

to be done to improve the material before it can be used in plantation. A series of accumulated released profile of cloprop anion from the interlamellae of the nanocomposite into the sodium phosphate aqueous solutions are done at various initial concentrations of $0.002 \mathrm{M}, 0.005$ $\mathrm{M}$ and $0.008 \mathrm{M}$.

As shown in the figure, a rapid release was found in all solutions at the beginning of time, followed by a more sustained release. The release profile of cloprop from cloprop-LDH and cloprop-ZLH nanocomposite shows an increasing value of accumulated release percentage as the concentration of the release solution was increased. This observation can be due to the many sacrificial anions which act as driving force for the release of cloprop anion from nanocomposite interlayer to aqueous solution. These sacrificial anions have high affinity to- wards the interlayer nanocomposite compared to the existing counter anion, resulting in ion exchange taking place [12]. At higher concentration of the anions in the aqueous media, more ion exchange process is obtained and a faster rate can be observed. The maximum accumulated release of cloprop $(0.008 \mathrm{M})$ into the me- dium can be achieved at around 600 and 200 min, re- spectively for both cloprop from cloprop-LDH, cloprop-ZLH nanocomposite with the percentage of $86 \%$ and $91 \%$. A fast release of cloprop anion from its nanocomposite could be due to high density of phosphate anion leading to a high formation of electrostatic interaction between phosphate anion with the positive charged layer of layered hydroxide material in the ion exchange process.

The release profile showed the accumulated release of cloprop from cloprop-LDH is slightly lower than cloprop-ZLH nanocomposite. The differences of the release profile were due to the crystallinity of the synthesized nanocomposite which refers to PXRD pattern for cloprop-ZLH nanocomposite. It shows high crystallinity than cloprop-LDH with the basal spacing of $22.7 \AA$ and $21.0 \AA$, respectively. High crystallinity material resulted of well-ordered arrangement of anion in the host during the intercalation process. Release of the intercalated guest from nanocomposite with high crystallinity and larger particle size would be slower than the ones with lower crystallinity and smaller particle size. This is due to the stability of the anion arrangement as well the less surface accessibility of the nanocomposite material to be ion exchanged with the incoming anion from medium. This explains the slightly different release rates between the cloprop-ZLH and cloprop-LDH. The method of preparation plays an important role in determining the physico-chemical properties of the resulting nanocomposites, in particular their surface properties and release behaviour of the guest anions [12].

\subsection{Kinetic Study}

Release kinetic studies of cloprop from its nanocomposites into sodium phosphate solutions were analyzed by applying four different kinetic models in order to study the behaviour of the release process.

It was suggested that the release of guest anion from the nanocomposite could be best described either by dissolution of LDH $[18,19]$ or by diffusion through the LDH $[20,21]$. The methods used are zeroth order (Equation (1)) [22], first order (Equation (2)) [23], pseudosecond order (Equation (3)) [24] and parabolic diffusion (Equation (4)) [21], for which the equations are given below. The $x$ is the percentage release of herbicides anion at time $t, M_{i}$ and $M_{f}$ are the initial and final concentrations of herbicides anions, respectively and $C$ is a constant. The parameter correlation coefficients, $r^{2}$ rate 
Tab le 2. TGA-DTG results for cloprop-LDH, cloprop-ZLH and cloprop anion.

\begin{tabular}{ccccc}
\hline \multicolumn{5}{c}{ Weight loss $(\%)$} \\
\hline Temperature & $35-200\left({ }^{\circ} \mathrm{C}\right)$ & $201-600\left({ }^{\circ} \mathrm{C}\right)$ & $601-1000\left({ }^{\circ} \mathrm{C}\right)$ & Total weight loss $(\%)$ \\
Cloprop-LDH & $16.5 \mathrm{~T}_{\max }=191^{\circ} \mathrm{C}$ & $31.7 \mathrm{~T}_{\max }=350^{\circ} \mathrm{C}$ & $20.5 \mathrm{~T}_{\max }=860^{\circ} \mathrm{C}$ & 68.7 \\
Cloprop-ZLH & $10.7 \mathrm{~T}_{\max }=167^{\circ} \mathrm{C} \mathrm{C}$ & $26.1 \mathrm{~T}_{\max }=381^{\circ} \mathrm{C}$ & - & 36.8 \\
Cloprop & - & $98.3 \mathrm{~T}_{\max }=204^{\circ} \mathrm{C}$ & - & 98.3 \\
\hline
\end{tabular}

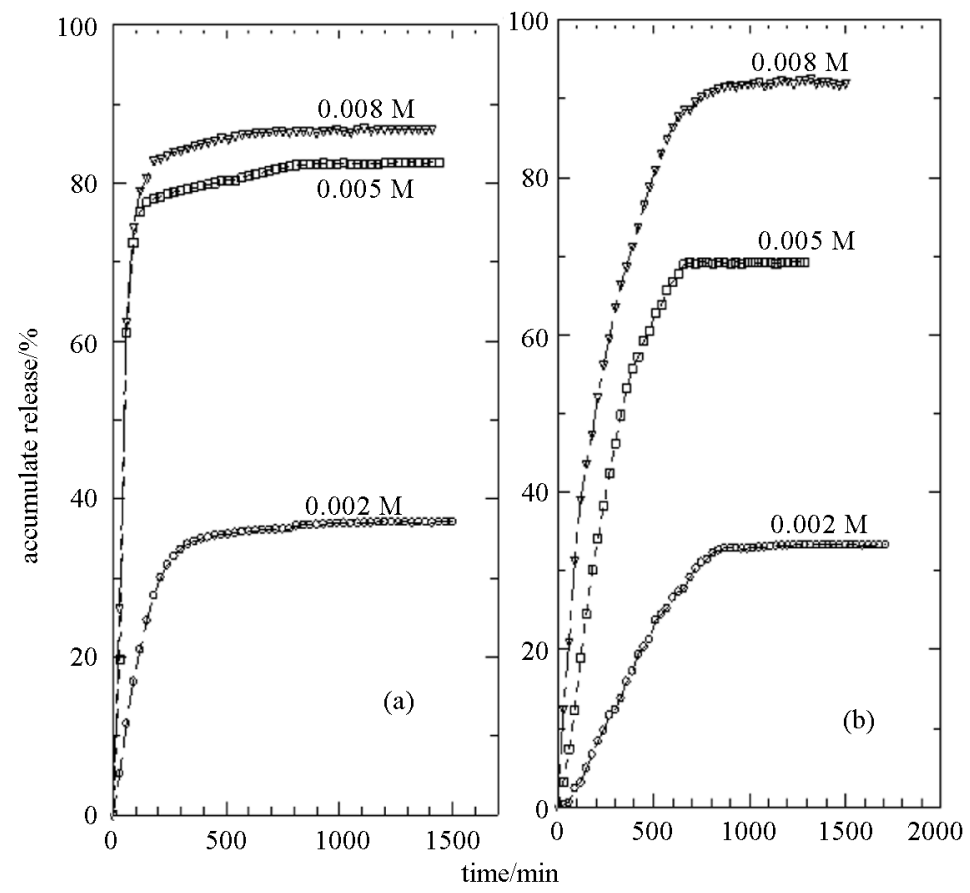

Figure 4. Release profile of clorop from the interlamellae of the clopropLDH (a) and cloprop-ZLH (b) nanocomposite into aqueous solutions containing various concentrations of $\mathrm{Na}_{3} \mathrm{PO}_{4}$.

constants, $k$ and $t_{1 / 2}$ values (the time required for $50 \%$ of cloprop to be released from nanocomposites) are calculated from the corresponding equations.

$$
\begin{gathered}
x=t+c \\
-\log \left(1-M_{i} / M_{f}\right)=t+C \\
t / M_{i}=1 / M_{f}^{2}+t / M_{f} \\
M_{i} / M_{f}=k t^{0.5}+C
\end{gathered}
$$

The extent of time determined to gauge the values of cloprop release fitted into the equation was fixed at 0 to1000 minutes.

Based on the four kinetic models above, the fitting results of cloprop release profiles are given in Figures 5 and 6 and Table 3. It can be seen in Figure 5 that the best fit is the plot of $t / M_{i}$ against time which shows an agreement with pseudo-second order kinetic model for cloprop-LDH in all sodium phosphate solution as the evidence of linearization of other models such as zeroth order, first order and parabolic diffusion do not fit nicely to the experimental data. On the other hand, the release of cloprop from cloprop-ZLH into aqueous solution containing phosphate anion showed a good fitting with parabolic diffusion model as evident by high $r^{2}$ values compared to first, zeroth and pseudo-second order (Figure 6).

Generally, the parabolic diffusion model elucidates that the release process is controlled by intra particle diffusion or surface diffusion. Therefore, it could be suggested that the results indicate the external surface diffusion or the intra particle diffusion via ion exchange which is the rate-determining step in the release process [25]. These results indicate that LDH and ZLH can be used to host a model guest, cloprop for their with controlled release properties.

For all the nanocomposites, the $t_{1 / 2}$ values that is the time taken for the herbicides anion concentration to increase to one-half of its initial values decrease as the concentration of the sodium phosphate increases. This is 

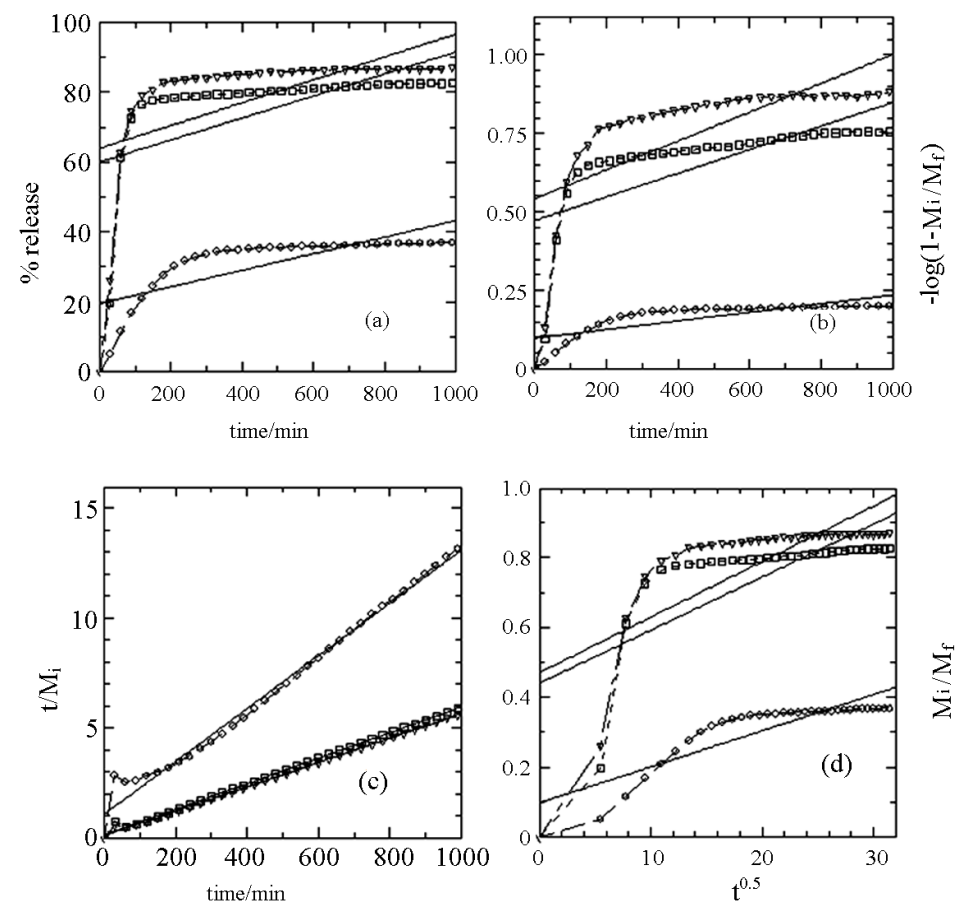

Figure 5. Fitting of the data of cloprop released into aqueous solutions containing various concentrations of $\mathrm{Na}_{3} \mathrm{PO}_{4} ; 0.002 \mathrm{M}$ (circles), $0.005 \mathrm{M}$ (squares) and $0.008 \mathrm{M}$ (triangles) to the zeroth (a), first (b) and pseudo-second order (c) kinetics, and parabolic diffusion (d) for cloprop-LDH (t $=0-1000 \mathrm{~min})$.
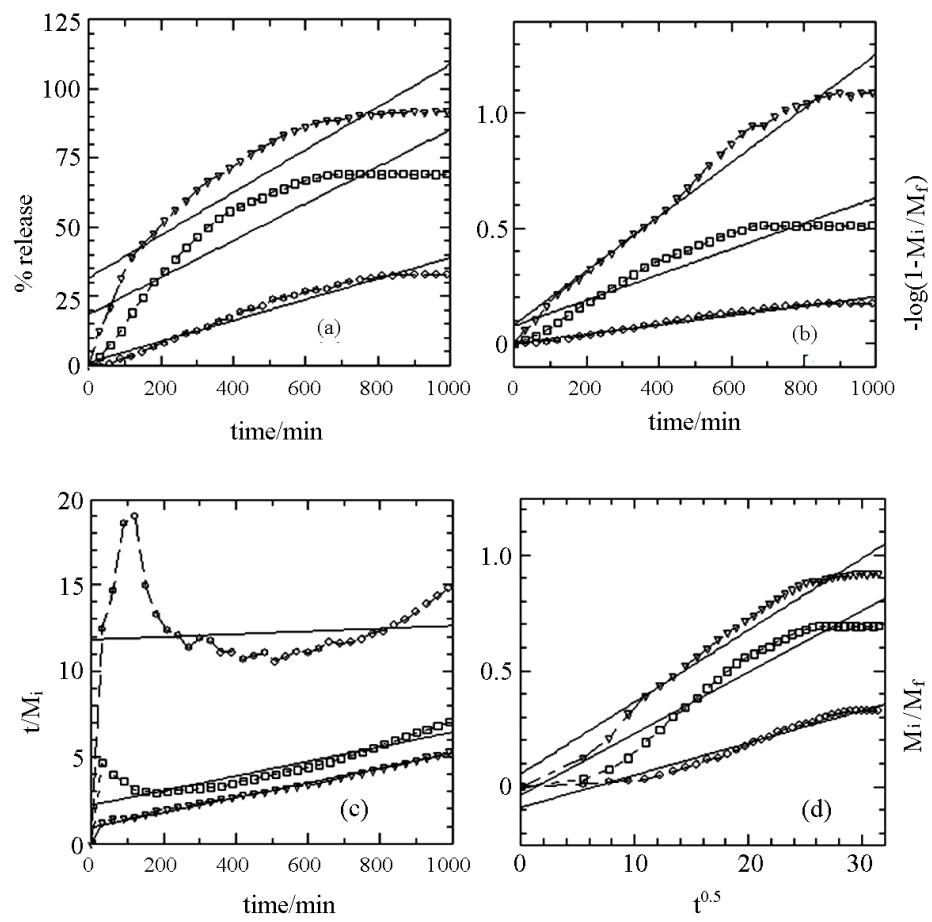

Figure 6. Fitting of the data of cloprop released into aqueous solutions containing various concentrations of $\mathrm{Na}_{3} \mathrm{PO}_{4} ; 0.002 \mathrm{M}$ (circles), $0.005 \mathrm{M}$ (squares) and $0.008 \mathrm{M}$ (triangles) to the zeroth (a), first (b) and pseudo-second order (c) kinetics, and parabolic diffusion (d) for cloprop-ZLH (t = $0-1000 \mathrm{~min}$ ). 
Table 3. Rate constants, half life $\left(\mathrm{t}_{1 / 2}\right)$ and correlation coefficients obtained from the fitting of the data of cloprop release from cloprop-LDH and cloprop-ZLH into $\mathrm{Na}_{3} \mathrm{PO}_{4}$ solutions.

\begin{tabular}{|c|c|c|c|c|c|c|}
\hline \multicolumn{7}{|c|}{ Cloprop-LDH nanocomposite } \\
\hline $\mathrm{Na}_{3} \mathrm{PO}_{4}\left(\mathrm{~mol} \cdot \mathrm{L}^{-1}\right)$ & Zeroth Order & First Order & Parabolic Diffusion & \multicolumn{3}{|c|}{ Pseudo second Order } \\
\hline \multicolumn{4}{|c|}{$r^{2}$} & $r^{2}$ & $\mathrm{k}$ & $t_{1 / 2}$ \\
\hline 0.002 & 0.552 & 0.590 & 0.765 & 0.989 & 0.010 & 95 \\
\hline 0.005 & 0.290 & 0.439 & 0.492 & 0.998 & 0.015 & 25 \\
\hline 0.008 & 0.291 & 0.454 & 0.501 & 0.999 & 0.015 & 19 \\
\hline \multicolumn{7}{|c|}{ Cloprop-ZLH nanocomposite } \\
\hline \multirow[t]{2}{*}{$\mathrm{Na}_{3} \mathrm{PO}_{4}\left(\mathrm{~mol} \cdot \mathrm{L}^{-1}\right)$} & Zeroth Order & First Order & Pseudo second Order & \multicolumn{3}{|c|}{ Parabolic Diffusion } \\
\hline & & & & $r^{2}$ & $\mathrm{k}$ & $t_{1 / 2}$ \\
\hline 0.002 & 0.961 & 0.973 & 0.0067 & 0.956 & 0.014 & 1801 \\
\hline 0.005 & 0.812 & 0.886 & 0.758 & 0.930 & 0.027 & 408 \\
\hline 0.008 & 0.825 & 0.974 & 0.979 & 0.956 & 0.031 & 207 \\
\hline
\end{tabular}

Unit: $\mathrm{k}\left(\mathrm{mg}^{-1} \mathrm{Ls}^{-1}\right), \mathrm{t}_{1 / 2}(\mathrm{~min})$.

obviously because as the concentration of the phosphate increases, more phosphate anions are available to be ion exchanged with cloprop anion, resulting in lower values of $t_{1 / 2}$. This pattern is similar to the $t_{1 / 2}$ values for the release of acetochlor from clay/CMC gel formulations [26]. The results demonstrate the zinc layered hydroxide and layered double hydroxide material are effective inorganic matrix for the herbicides anions storage and possesses controlled delivery at the required time, which is recommendable for the agricultural purposes.

\section{CONCLUSION}

The intercalation of cloprop phenoxyherbicides anion into Zn/Al-layered double hydroxide and zinc-layered hydroxide using co-precipitation and direct reaction method, respectively, was synthesized. This was proven through the expansion of $d$ spacing in PXRD pattern with value of $21.0 \AA$ (cloprop-LDH) and $22.7 \AA$ (clopropZLH). Percentage release of chlorprop from interlayer of cloprop-ZLH nanocomposite was slightly higher than that from cloprop-LDH nanocomposite in controlled release study due to the high crystallinity of cloprop-ZLH. The release behavior of cloprop from its nanocomposites into phosphate solution followed the pseudo-second-order for cloprop-LDH and parabolic diffusion for clopropZLH. The present study shows that both layered hydroxide materials are compatible inorganic matrix proposed for controlled release formulation of herbicides in agriculture.

\section{ACKNOWLEDGEMENTS}

The support of the research by KPM under RACE Grant no. 2012-
0151-101-62. NH thanks UPSI for all affords and support in this research.

\section{REFERENCES}

[1] Cardoso, L.P. and Valim, J.B. (2006) Study of acids removal by calcined Mg-Al- $\mathrm{CO}_{3}-\mathrm{LDH}$. Journal of Physics and Chemistry of Solid, 67, 987-993.

http://dx.doi.org/10.1016/j.jpcs.2006.01.015

[2] Hermosin, M.C., Calderon, M.J., Aguer, J.P. and Cornejo, J. (2001) Organoclays for controlled release of the herbicide fenuron. Pest Management Science, 57, 803-809. http://dx.doi.org/10.1002/ps.359

[3] Cavani, F., Triffiro, F. and Vaccani, A. (1991) Hydrotalcite-type anionic clays: Preparation, properties and application. Catalysis Today, 11, 173-301. http://dx.doi.org/10.1016/0920-5861(91)80068-K

[4] Reichle, W.T. (1986) Synthesis of anionic clay minerals (mixed metal hydroxides, hydrotalcite). Solid State Ionics, 22, 135-142. http://dx.doi.org/10.1016/0167-2738(86)90067-6

[5] Constantino, V.R.L. and Pinnavaia, T.J. (1995) Basic properties of $\mathrm{Mg}^{2+}{ }_{1-\mathrm{x}} \mathrm{Al}^{3+}{ }_{\mathrm{x}}$ layered double hydroxide intercalated by carbonate, hydroxide, chloride and sulphate ions. Inorganic Chemistry, 34, 883-892. http://dx.doi.org/10.1021/ic00108a020

[6] Khan, S.B., Liu, C., Jang, E.S., Akhtar, K. and Han, H. (2011) Encapsulation of organic UV ray absorbents into layered double hydroxide for photochemical properties. Materials Letters, 65, 2923-2926.

http://dx.doi.org/10.1016/j.matlet.2011.03.107

[7] Isa, I.M., Dahlan, S.N.A., Hashim, N., Ahmad, M. and Ghani, S.A. (2012) Electrochemical sensor for cobalt(II) by modified carbon paste electrode with Zn/A1-2(3Chlorophenoxy) propionate Nanocomposite. Internation- 
al Journal of Electrochemical Science, 7, 7797-7808.

[8] Isa, I.M., Sohaimi, N.M., Hashim, N. Kamari, A., Mohamed, A., Ahmad, M., Ghani, S.A. and Suyanta (2013) Determination of salicylate ion by potentiometric membrance electrode based on zinc aluminium layered double hydroxides-4(2,4-dichlorophenoxy)butyrate nanocomposite. International Journal of Electrochemical Science, 8, 2112-2121.

[9] Li, J., Li, Y. and Dong, H. (2008) Controlled release of herbicide acetochlor from clay/carboxylmethylcellulose gel formulations. Journal of Agricultural and Food Chemistry, 56, 1336-1342.

[10] Cordeiro, C.S., Arizaga, G.G.C., Ramos, L.P. and Wypych, F. (2008) A new zinc hydroxide nitrate heterogeneous catalyst for the esterification of free fatty acids and the transesterification of vegetable oils. Catalysis Communications,

9 , 2140-2143. http://dx.doi.org/10.1016/j.catcom.2008.04.0 $\underline{15}$

[11] Mohsin, S.M.N., Hussein, M.Z., Sarijo, S.H., Fakurazi, S., Arulselvan, P. and Hin, T.Y.Y. (2013) Synthesis of (cinnamate-zinc layered hydroxide) intercalation compound for sunscreen application. Chemistry Central Journal, 7, 26. http://dx.doi.org/10.1186/1752-153X-7-26

[12] Hussein, M.Z., Hashim, N., Yahaya, A.H. and Zainal, Z. (2009) Controlled release formulation of pesticide agrochemical based on 4-(2,4-dichlorophenoxy)butyrate nanohybrid. Journal of Nanoscience and Nanotechnology, 9, 2140-2147. http://dx.doi.org/10.1166/jnn.2009.445

[13] He, J., Wei, M., Li, B., Kang, Y., Evans, D.G. and Duan, X. (2006) Layered Double Hydroxide. Structure and bonding: Preparation of layered double hydroxides. Springer-Verlag, Berlin, Heidelberg. http://dx.doi.org/10.1007/430_006

[14] $\mathrm{Xu}, \mathrm{S}$. and Wang, Z.L. (2011) One-dimensional ZnO nanostructures: Solution growth and functional properties. Nano Research, 4, 1013-1098. http://dx.doi.org/10.1007/s12274-011-0160-7

[15] Ragavan, A., Khan, A.I. and O’Hare, D. (2006) Intercalation and controlled release of 2,4-dichlorophenoxyacetic acid using rhombohedral $\left[\mathrm{LiAl}_{2}(\mathrm{OH})_{6}\right] \mathrm{Cl} \cdot \mathrm{xH}_{2} \mathrm{O}$. Journal of Physics Chemistry and Solids, 67, 983-968. http://dx.doi.org/10.1039/b610766d

[16] Hussein, M.Z., Sarijo, S.H., Yahaya, A.H. and Zainal, Z. (2007) Synthesis of 4-chlorophenoxyacetate-zinc-aluminium layered double hydroxide nanocomposite: Physicochemical and controlled release properties. Journal of Nanoscience and Nanotechnology, 7, 2852-2862. http://dx.doi.org/10.1166/jnn.2007.613
[17] Hussein, M.Z., Jubri, Z.B., Zainal, Z. and Yahaya, A.H. (2004) Pamoate intercalated Zn-Al layered double hydroxide for the formation of layered organic-inorganic intercalate. Materials Science-Poland, 22, 57-67.

[18] Ambrogi, V., Fardella, G. and Grandolini, G. (2001) Intercalation compounds of hydrotalicite-like anionic clays with anti flammatory agents: I. Intercalation and in vitro release of ibufuren. International Journal of Pharmacy, 220, 23-32. http://dx.doi.org/10.1016/S0378-5173(01)00629-9

[19] Hussein, M.Z., Zainal, Z., Yahaya, A.H. and Foo, D.W.V. (2002) Controlled release of plant growth regulator $\alpha$ naphthalane-acetate from the lamella of Zn-Al-layered double hydroxide nanocomposite. Journal of Controlled Release, 82, 417-427. http://dx.doi.org/10.1016/S0168-3659(02)00172-4

[20] Gunawan, P. and Xu, R. (2008) Direct control of drug release behavior from layered double hydroxides through particle interactions. Journal of Pharmaceutical Sciences, 97, 4367-4378. http://dx.doi.org/10.1002/jps.21321

[21] Kodama, T., Harada, Y., Ueda, M., Shimizu, K., Shuto, K. and Komarneni, S. (2001) Selective exchange and fixation of strontium ions with ultrafine Na-4-mica. Langmuir, 17, 4881-4886. http://dx.doi.org/10.1021/la001774w

[22] Costa, P. and Lobo, J.M.S. (2001) Modeling and comparison of dissolution profiles. European Journal of Pharmaceutical Sciences, 13, 123-133. http://dx.doi.org/10.1016/S0928-0987(01)00095-1

[23] Qiu, H., Lv, L., Pan, B.C., Zhang, Q.J., Zhang, W.M. and Zhang, Q.X. (2009) Critical review in adsorption kinetic models. Journal of Zhejiang University Science A, 10, 716-724. http://dx.doi.org/10.1631/jzus.A0820524

[24] Ho, Y.S. (2006) Review of second-order models for adsorption systems. Journal of Hazardous Materials, B136, 681-689. http://dx.doi.org/10.1016/j.jhazmat.2005.12.043

[25] Kong, X., Shi, S., Han, J., Zhu, F., Wei, M. and Duan, X. (2010) Preparation of Glycy-l-Tyrosine intercalated layered double hydroxide film and its in vitro release behavior. Chemical Engineering Journal, 157, 598-604. http://dx.doi.org/10.1016/j.cej.2010.01.016

[26] Li, W., Yan, D., Gao, R., Lu, J., Wei, M. and Duan, X. (2013) Recent advances in stimuli-responsive photofunctional materials based on accommodation of chromophore into layered double hydroxide nanogallery. Journal of Nanomaterials, 2013, $14 \mathrm{p}$. http://dx.doi.org/10.1155/2013/586462 